\title{
Estoque de carbono em área de cana-de-açúcar sob diferentes sistemas de manejo
}

\section{Icaro S. Matsuda Tamashiro*, Zigomar M. de Souza, Camila V. Vieira Farhate, Lenon H Lovera, Ingrid N. de Oliveira}

\section{Resumo}

Esse estudo trata-se dos resultados e um experimento de campo desenvolvido na região sudeste do Brasil, com objetivo de avaliar o estoque de carbono no solo em área de cana-de-açúcar sob diferentes plantas de cobertura e sistemas de preparo do solo, usando como referência o sistema convencional.

\section{Palavras-chave: \\ Matéria orgânica, crotalária juncea, sistemas de manejo conservacionistas.}

\section{Introdução}

Atualmente o Brasil destaca-se no cenário mundial como o maior produtor de cana-de-açúcar e, suas lavouras continuam em expansão frente a uma crescente demanda por bioetanol, impulsionado por questões ambientais, geopolíticas e econômicas (LAPOLA et al., 2010). Nesse contexto, pesquisas que visem o aumento da produtividade da cana-de-açúcar e a redução dos seus custos de produção são fundamentais.

O carbono do solo, por sua vez, desempenha um papel importante na manutenção da produtividade agrícola, por promover melhorias nos atributos físicos, químicos e biológicos, permitindo um aumento na produtividade e redução de insumos agrícolas (CONCEIÇÃO et al., 2017).

Assim, o objetivo desse estudo foi quantificar o estoque de carbono no solo em área de cana-de-açúcar sob diferentes plantas de cobertura e sistemas de preparo do solo, usando como referência o sistema convencional.

\section{Resultados e Discussão}

Esse estudo foi realizado em condições de campo, em uma área experimental no município de Ibitinga, São Paulo, Brasil (Figura 1).

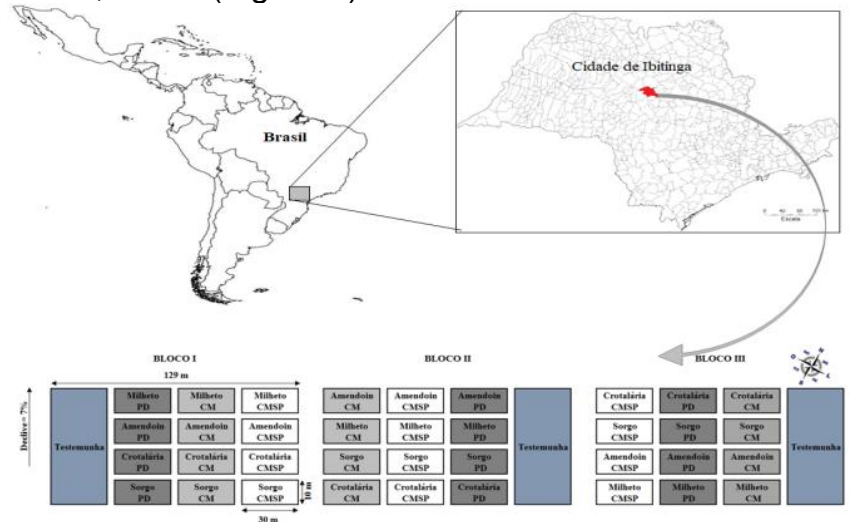

Figura 1. Localização da área experimental no município de Ibitinga, em relação ao estado de São Paulo e ao Brasil.

O estoque de carbono do solo foi avaliado durante dois ciclos de cultivo da cana-de-açúcar, cana planta e soca, em duas profundidades distintas, a saber: 0,00-005 e $0,05-0,10 \mathrm{~m}$.

Independente do ciclo de cultivo, as plantas de cobertura não influenciaram o estoque de carbono na camada de 0,00-005 m. No entanto, na camada de 0,05-0,10 m durante o ciclo de cultivo da cana planta, observa-se que
- uso da crotalária proporcionou maior estoque de carbono que as demais plantas de cobertura (Tabela 1). Em relação ao sistema de preparo do solo, para a camada de 0,00-0,05 $\mathrm{m}$ durante o ciclo de produção da cana planta, o uso do plantio direto (SP1) aumentou o estoque de carbono do solo, ocorrendo redução no sistema de preparo convencional (testemunha).

Tabela 1. Estoque de carbono $\left(\mathrm{Mg} \mathrm{ha}^{-1}\right)$ em função de diferentes plantas de cobertura e sistemas de preparos de solo.

\begin{tabular}{|c|c|c|c|c|}
\hline \multirow[t]{2}{*}{ Tratamento } & \multicolumn{2}{|c|}{$0,00-0,05$} & \multicolumn{2}{|c|}{$0,05-0,10$} \\
\hline & $2015 / 16$ & $2016 / 17$ & $2015 / 16$ & $2016 / 17$ \\
\hline \multicolumn{5}{|c|}{ Planta de cobertura } \\
\hline Amendoim & $4,52 \mathrm{a}$ & $8,03 \mathrm{a}$ & $4,25 \mathrm{abc}$ & $4,89 \mathrm{a}$ \\
\hline Crotalária & $4,64 \mathrm{a}$ & $6,91 \mathrm{a}$ & $5,10 \mathrm{a}$ & $5,83 a$ \\
\hline Milheto & $5,23 \mathrm{a}$ & $7,48 \mathrm{a}$ & $4,92 a b$ & $5,71 \mathrm{a}$ \\
\hline Sorgo & $4,17 \mathrm{a}$ & $7,80 \mathrm{a}$ & $3,70 \mathrm{c}$ & $5,64 \mathrm{a}$ \\
\hline Testemunh & $3,64 a$ & $5,94 a$ & $4,01 \mathrm{bc}$ & $6,22 a$ \\
\hline $\mathrm{CV}$ & 29,53 & 30,59 & 16,48 & 21,41 \\
\hline \multicolumn{5}{|c|}{ Sistema de preparo do solo } \\
\hline SP1 & $5,20 \mathrm{a}$ & $7,78 \mathrm{a}$ & $4,41 \mathrm{a}$ & $5,36 a$ \\
\hline SP2 & $4,11 \mathrm{ab}$ & $6,88 \mathrm{a}$ & $4,51 \mathrm{a}$ & $5,13 a$ \\
\hline SP3 & $4,60 \mathrm{ab}$ & $8,01 \mathrm{a}$ & $4,56 \mathrm{a}$ & $6,06 \mathrm{a}$ \\
\hline Testemunh & $3.64 \mathrm{~b}$ & $5.94 a$ & $4.01 \mathrm{a}$ & $6.22 \mathrm{a}$ \\
\hline $\mathrm{CV}$ & 28,35 & 31,41 & 15,94 & 20,07 \\
\hline $\begin{array}{l}\text { SP1 = } \\
\text { subsola } \\
\text { de mes } \\
\text { probabi }\end{array}$ & & & & $\begin{array}{l}\text { imo com } \\
\text { seguidas } \\
\text { a } 5 \% \text { de }\end{array}$ \\
\hline
\end{tabular}

\section{Conclusões}

O uso de crotalária juncea e plantio direto para o cultivo de cana-de-açúcar favorecem o aumento do estoque de carbono no solo, ocorrendo redução no sistema de preparo convencional (testemunha).

\section{Agradecimentos}

Os autores agradecem o apoio financeiro pelo Conselho Nacional de Desenvolvimento Científico e Tecnológico (CNPq) e, a Usina Santa Fé pelo fornecimento da área de estudos.

Lapola, D.M.; Schaldacha, R.; Alcamoa, J.; Bondeaud, A.; Kocha, J.; Koelkinga. A. Priesse, J.A. Proc. Natl. Acad. Sci. U. S. A. 2010, 107, 3388-3393.

Conceição, M.G.; Matos, E.S.; Bidone, E.D.; Rodrigues, R.A.R.; Cordeiro, R.C. Agric. Sci. 2017, 8, 904-913. 